\title{
Comissão Intra-Hospitalar de Doação de Órgãos e Tecidos para Transplante: vivência dos enfermeiros
}

\author{
Intra-hospital commission on organ and tissue donation for transplant: nurses' experience \\ Comisión intrahospitalaria de donación de órganos y tejidos para trasplante: vivencia de los enfermeros
}

\author{
Tatiane Ribeiro da Silva'; Marcelo da Silva Alves"; Patrícia Rodrigues Braz"II'; Fábio da Costa Carbogim"
}

\begin{abstract}
RESUMO
Objetivo: compreender as vivências de enfermeiros da Comissão Intra-Hospitalar de Doação de Órgãos e Tecidos para Transplante (CIHDOTT) em uma instituição hospitalar privada da Zona da Mata Mineira. Método: estudo descritivo, qualitativo, realizado com 11 enfermeiros, por meio de entrevista semiestruturada realizada entre julho e dezembro de 2017. A análise de conteúdo foi utilizada como referencial metodológico para o estudo dos depoimentos. Resultados: dos 11 participantes, $72 \%$ eram mulheres e $28 \%$ homens, com média de idade de 35 anos. Quanto à raça, oito se autodeclararam brancos e três, negros. O tempo de trabalho na comissão variou de dois meses a seis anos, com média de dois anos e sete meses. A partir da análise de conteúdo dos depoimentos, emergiram três categorias: o ser enfermeiro da comissão; abordagem familiar e treinamento e capacitação. Conclusão: o estudo demonstrou que a vivência na comissão é permeada por fragilidades e que a identificação delas propicia o desenvolvimento de estratégias para aprimoramento do processo nas instituições.
\end{abstract} Descritores: Enfermagem; transplante; morte encefálica; doação de órgãos.

\section{ABSTRACT}

Objective: to understand the experiences of nurses on the Intra-Hospital Committee on Organ and Tissue Donation for Transplant (CIHDOTT) at a private hospital in the Zona da Mata of Minas Gerais. Method: this descriptive, qualitative study was conducted by semistructured interview of 11 nurses between July and December 2017. Content analysis was used as a methodological frame of reference for studying the transcripts. Results: of the eleven participants, $72 \%$ were women and $28 \%$ were men; average age was 35 years; and eight declared themselves white, and three, black. Length on service on the committee ranged from two months to six years, and averaged 2 years and 7 months. From the content analysis of the testimonies, three categories emerged: being a nurse on the committee; family approach; and training and capacity building. Conclusion: the study demonstrated that the experience on the committee is permeated by weaknesses, identification of which facilitates the development of strategies to improve the process in the institutions.

Descriptors: Nursing; transplantation; brain death; tissue and organ procurement.

\section{RESUMEN}

Objetivo: comprender las vivencias de enfermeros de la Comisión Intrahospitalaria de Donación de Órganos y Tejidos para Trasplante (CIHDOTT) en una institución hospitalaria privada de la Zona da Mata de Minas Gerais. Método: estudio descriptivo, cualitativo, realizado junto a 11 enfermeros, por medio de entrevista semiestructurada entre julio y diciembre de 2017. El análisis de contenido se utilizó como referencial metodológico para el estudio de las declaraciones. Resultados: de los once participantes, el $72 \%$ era de mujeres y el $28 \%$ de hombres, con un promedio de edad de 35 años. En cuanto a la raza, ocho se autodeclararon blancos y tres negros. El tiempo de trabajo en la comisión varió de dos meses a seis años, con un promedio de 2 años y 7 meses. A partir del análisis de contenido de las declaraciones, surgieron tres categorías: el ser enfermero de la comisión; enfoque familiar y formación y capacitación. Conclusión: el estudio demostró que la vivencia en la comisión está impregnada por fragilidades y que su identificación propicia el desarrollo de estrategias para perfeccionar el proceso en las instituciones.

Descriptores: Enfermería; trasplante; muerte encefálica; obtención de tejidos y órganos.

\section{INTRODUÇÃO}

O transplante de órgãos evoluiu de uma técnica arriscada e não regulamentada para uma terapêutica técnico-científica eficaz, com resultados promissores a pacientes portadores de doenças crônicas ou terminais. Tal procedimento cirúrgico viabiliza a substituição de órgãos como coração, pulmão, rins, fígado, pâncreas, intestino e tecidos, medula óssea, ossos, válvulas, músculos, pele, córneas, veias e artérias ${ }^{1}$.

Conforme divulgado pela Associação Brasileira de Transplantes (ABTO), o Brasil possui um programa públi-

'Enfermeira. Especialista. Mestre em Enfermagem pela Universidade Federal de Juiz de Fora, Minas Gerais, Brasil. E-mail: tatyanejf@hotmail.com

"Enfermeiro. Doutor em Saúde Coletiva. Professor Associado da Faculdade de Enfermagem da Universidade Federal de Juiz de Fora, Minas Gerais, Brasil. E-mail: enfermar@oi.com.br '"Enfermeira. Mestre em Enfermagem pela Universidade Federal de Juiz de Fora, Minas Gerais, Brasil. E-mail: patibrazenf@gmail.com

IvEnfermeiro. Doutor em Ciências pela Escola de Enfermagem da USP. Professor Adjunto I da Faculdade de Enfermagem da Universidade Federal de Juiz de Fora, Minas Gerais, Brasil. E-mail: fabiocarbogim@gmail.com 
co de transplantes de órgãos adequado e estruturado, porém ineficaz para atender toda a demanda, fato esse justificado pelo aumento das filas de espera (na lista de espera de 2018 já constam 32.066 pacientes) e a alta taxa de não autorização para doação de órgãos e/ou tecidos pelos familiares ${ }^{2}$.

A necessidade de elevar o número de transplantes é uma prioridade mundial. Nesse contexto, embora esse número tenha aumentado, o Brasil permaneceu com quantitativo de transplantes abaixo do esperado comparado a outros países ${ }^{3-5}$. Países como Espanha, Portugal e Itália vêm intensificando o aprimoramento dos programas de transplantes ${ }^{5}$.

No Brasil, em atendimento à Portaria no 2.600, de 21 de outubro de 2009, as Comissões Intra-Hospitalares de Doação de Órgãos e Tecidos para Transplantes (CIHDOTT) são representações internas nas instituições hospitalares. Dessa forma, a CIHDOTT é obrigatória em instituições incluídas nos seguintes perfis: tipo I - estabelecimentos com até 200 óbitos por ano e leitos para assistência respiratória; tipo II - estabelecimentos com referência para trauma e/ ou neurologia, com menos de mil óbitos por ano ou estabelecimento não oncológico com 200 a mil óbitos por ano; e tipo III - estabelecimento não oncológico com mais de mil óbitos por ano ou estabelecimento com, pelo menos, um programa de transplante de órgãos ${ }^{6}$.

O enfermeiro está diretamente envolvido no processo de transplante de órgãos e sua atuação é regulamentada pelo Conselho Federal de Enfermagem (Cofen) por meio da Resolução n. 292/2004, que dispõe que cabe a esse profissional o planejamento, a execução, a coordenação, a supervisão e a avaliação dos procedimentos de enfermagem prestados ao doador, bem como o planejamento e a implementação de ações que resultem na otimização da doação e captação de órgãos e tecidos para fins de transplante ${ }^{7}$.

Um estudo de revisão integrativa relacionado à produção científica referente à doação de órgãos e transplantes revelou que as publicações de enfermagem se concentram, em sua maioria, relacionadas ao transplante hepático e renal. O estudo traz evidências de que existe uma lacuna no conhecimento referente à vivência dos profissionais de saúde em comissões para transplantes ${ }^{8}$. Destarte, tornam-se importante no país estudos que descrevam e discutam as atividades desenvolvidas pelos enfermeiros da CIHDOTT. Desse modo, diante da escassez de estudos desse cunho, justifica-se a importância de pesquisas que descrevam e discutam as atividades desenvolvidas pelos enfermeiros da CIHDOTT no país. Diante do exposto, a pesquisa teve como objetivo compreender as vivências de enfermeiros inseridos em uma CIHDOTT.

\section{REVISÃo DE LITERATURA}

As CIHDOTTs no âmbito das instituições de saúde têm como atribuições organizar o protocolo assistencial de doação de órgãos, oferecer aos familiares de pacien- tes falecidos a possibilidade da doação de córneas e outros tecidos, articular-se com as equipes das unidades de tratamento intensivo e urgência e emergência para identificar os potenciais doadores e verificar morte encefálica. Após isso, efetivam a doação, notificando-a e promovendo o registro de todos os casos com diagnóstico de morte encefálica, mesmo não se tratando de possíveis doadores de órgãos e tecidos. Além disso, registram o número de óbitos ocorridos na instituição, articulam-se com a respectiva Central de Notificação, Captação e Distribuição de Órgãos e Tecidos (CNCDO), e/ou bancos de tecidos de sua região para organizar o processo de doação e captação de órgãos e tecidos, realizar a educação permanente dos funcionários da instituição no que tange a esse processo, implementar programas de qualidade para que seja possível mensurar o trabalho desenvolvido pelas equipes da CIHDOTT na instituição, bem como promover o acolhimento dos familiares durante todo o processo ${ }^{6}$.

Destaca-se a importância da educação familiar visto que grande parte da população recebe informações sobre transplantes somente por meio da mídia nos meses de campanha. Não há uma conscientização contínua, pouco se observa a influência de familiares, amigos ou profissionais de saúde no sentido de conscientizar as pessoas sobre a importância da doação de órgãos para salvar vidas. Assim é preciso ter qualidade na informação oferecida, pois a população bem informada irá favorecer a discussão sobre doação de órgãos nos ambientes familiares e entre amigos, desencadeando assim a promoção do ato de doar ${ }^{9}$.

Para que ocorra o transplante de órgãos com êxito, é imprescindível que sejam seguidas todas as etapas fundamentais do processo, tais como identificação do possível doador, notificação do caso à CNCDO, manutenção do potencial doador, avaliação para o quadro de morte encefálica, comunicação aos familiares acerca do quadro e realização da entrevista familiar, que irá resultar ou não na doação. O enfermeiro inserido na CIHDOTT atua nas referidas etapas, portanto se torna relevante a identificação das fragilidades inerentes a esse processo, de forma a elencar estratégias objetivando melhorias no processo de doação e transplante de órgãos ${ }^{10}$.

\section{Metodologia}

Trata-se de um estudo descritivo com abordagem qualitativa, desenvolvido na CIHDOTT de uma instituição hospitalar privada, localizada na Zona da Mata Mineira. A CIHDOTT da instituição é composta por 21 enfermeiros, dois psicólogos e dois médicos, entre esses, dois coordenadores, sendo um enfermeiro e um médico. De um total de 23 profissionais, participaram do estudo 11 enfermeiros atuantes na comissão.

Foram considerados critérios de inclusão no estudo: profissionais enfermeiros e membros da CIHDOTT mediante assinatura do Termo de Consentimento Livre 
e Esclarecido (TCLE). Como critérios de exclusão: profissionais de outras categorias, que se encontravam de licença, férias ou afastados e que se recusaram a participar da pesquisa. Assim, durante o processo de coleta de informações, havia um enfermeiro de férias, três enfermeiras de licença-maternidade, dois estavam se desligando da instituição e quatro se recusaram a participar da pesquisa. As informações foram obtidas mediante entrevista semiestruturada, realizada no período de julho a dezembro de 2017. As entrevistas foram gravadas, transcritas na íntegra, e os depoimentos foram organizados e analisados segundo referencial metodológico da análise de conteúdo ${ }^{11}$. Em seguida, foram elaboradas as seguintes categorias: o ser enfermeiro da comissão de transplante; abordagem familiar e treinamento e capacitação.

Bardin propõe três fases para análise das falas, a pré-análise, que tem como objetivo organizar o material de forma a sistematizar as ideias iniciais; a exploração do material, que consiste em definir as categorias e identificar as unidades de significado e a terceira fase, que consiste no tratamento dos resultados, inferência e interpretação, é o momento da análise crítica e reflexiva das informações.

Para preservar o anonimato dos participantes, foi definida como codinome a letra $\mathrm{E}$ seguida dos números alfanuméricos de 1 a 11 correspondentes a cada entrevista.

O presente estudo foi submetido ao Comitê de Ética em Pesquisa (CEP) da Universidade Federal de Juiz de Fora (UFJF) para análise e parecer, recebendo parecer favorável (CAAE n. 63257316.9.0000.5147) de 02 de maio de 2017. Foram seguidos todos os cuidados em relação à resolução n. 466/12 do Conselho Nacional de Saúde - Ministério da Saúde, que dispõe sobre Diretrizes e Normas Regulamentadoras de Pesquisas Envolvendo Seres Humanos ${ }^{12}$.

\section{RESULTAdos E Discussão}

Dos 11 participantes do estudo, $72 \%$ eram mulheres e $28 \%$ homens, a média de idade dos participantes foi de 35 anos, variando de 28 a 51 anos. Quanto à raça, oito se autodeclararam brancos e três, negros. O tempo de trabalho na comissão variou de dois meses a seis anos, com média de 2 anos e 7 meses. Os enfermeiros em sua totalidade informaram não possuir especialização na área de transplantes. O tempo de duração das entrevistas variou entre trinta minutos e duas horas.

A partir da análise de conteúdo dos depoimentos, emergiram três categorias tratadas a seguir.

\section{O ser enfermeiro da comissão}

As falas evidenciaram que o enfermeiro atuante na CIHDOTT é considerado profissional de referência e, apesar de existir uma equipe multiprofissional que compõe essa comissão, em todo o processo se dá sua atuação, presente na identificação do potencial doador, na entrevista familiar e na finalização do processo. Nesse sentido, os participantes reconhecem a importância do seu papel na CIHDOTT e que estão contribuindo para viabilizar o processo de doação.

Eu acho que o enfermeiro é uma pessoa de referência, uma pessoa específica para o cargo, se ele não estiver, a coisa se perde e não sabe quem irá fazer a abordagem naquele momento. (E1)

O enfermeiro que atua na CIHDOTT é extremamente importante, pois através de uma avaliação e uma abordagem bem feita é que vamos ter a possibilidade de uma doação de órgãos, culminando assim com uma vida salva. Os enfermeiros precisam entender que somos a "porta de entrada" dos transplantes e de grande importância na CIHDOTT. (E2)

Estudos evidenciam que o profissional atuante no processo de doação e transplantes percebe que seu trabalho é extremamente significativo, devido à possibilidade de salvar vidas e à oportunidade de acolhimento aos familiares do doador ${ }^{13,14}$.

Conforme depoimentos, os enfermeiros associam o processo de doação à ajuda e ao auxílio profissional ao próximo, ressaltam sentimentos como solidariedade e gratidão a ambos os protagonistas desse processo e destacam ainda a importância da atitude empática com objetivo de sensibilização para o processo de doação de órgãos.

Estar na CIHDOTT hoje significa mais que articular e organizar o processo de doação, detectar o possivel doador de tecidos ou órgãos, mais gratificante é saber que as doações vão ajudar muitos que estão sem esperança, que, recebendo o transplante, vão ter qualidade de vida. Nesse processo, o enfermeiro se coloca à frente, com um trabalho humanizado, obtendo conhecimento sobre o processo de morte. (E3)

Ser membro da CIHDOTT para mim hoje significa mais que uma oportunidade e sim uma gratidão por poder contribuir para que alguém possa viver diante de tamanha tristeza que é a perda de um ente querido. (E2)

A Teoria humanística de Paterson e Zdrad reforça a importância do estar-com, a interação entre duas pessoas através de uma experiência intersubjetiva em que ocorre o verdadeiro partilhar, a fim de que, nesse diálogo, alcance-se o relacionar-se com o estar presente e o encontrar-se ${ }^{15}$.

Para o enfermeiro desenvolver seu papel na CIHDOTT, torna-se imprescindível estabelecer um cuidado humanizado. Dessa forma, é importante ressaltar que o processo de humanização engloba vários aspectos, como atendimento ao paciente, condições de trabalho, além do cumprimento das necessidades básicas institucionais, tais como administrativas, físicas e humanas. O enfermeiro inserido neste cenário pode contribuir para que o cuidado prestado aos familiares e ao potencial doador esteja centrado na sensibilidade, na ciência e na arte ${ }^{16}$.

As práticas cotidianas relacionadas à humanização necessitam de um conhecimento prévio, além de possuírem caráter subjetivo, englobam diferentes significados. Para os profissionais, trata-se do cuidar com respeito, carinho, amor, empatia, acolhimento e diálogo, já no âmbito da produção acadêmica, esse cuidado humaniza- 
do envolve a criação de vínculo, qualidade e valorização dos trabalhadores ${ }^{16}$.

Outro ponto apresentado pelos participantes é a falta de reconhecimento profissional da atuação do enfermeiro e de sua importância no serviço. Os enfermeiros, embora estejam cientes da importância de sua prática, não se sentem valorizados profissionalmente por fazerem parte da comissão, fato que justifica a desmotivação na realização desse trabalho.

Eu vejo que a participação do enfermeiro quando ele é atuante faz muita diferença no serviço; primeiro eu acho que você tem que saber sua importância naquele serviço, porque, se você sabe que é importante, você dá importância para aquele serviço. (E1)

Acho que é importante fazer com que o enfermeiro entenda qual é o papel dele e como ele está inserido nessa CIHDOTT, mostrar para ele a sua importância na CIHDOTT. (E5)

Ser membro da comissão não tem grande significado para mim porque não houve melhoria em nada, eu esperava um mínimo de reconhecimento profissional, melhoria financeira, o que infelizmente não acontece. (E6)

O reconhecimento da profissão influencia diretamente o desempenho laboral, além disso, as implicações negativas levam a desmotivação e insatisfação no ambiente de trabalho. Quando o profissional se sente valorizado e reconhecido, o mesmo desempenha seu papel com comprometimento e satisfação, influenciando a qualidade da assistência ${ }^{17}$.

O enfermeiro é a pessoa de referência na comissão, neste contexto, existe uma real necessidade de revisitar continuamente a sua prática, a fim de recusar a simplificação e fragmentação do saber, pois o cuidado humano exige, além da técnica e tecnologia, escuta, sensibilidade e zelo. Atuar com o processo de transplante exige desenvolvimento de tais competências e habilidades a fim de melhorar a sua prática ${ }^{18}$.

\section{Abordagem familiar}

Os enfermeiros relataram suas percepções e vivências relacionadas ao momento da abordagem. Para esses enfermeiros a importância do acompanhamento dos familiares na abertura do protocolo de Morte Encefálica (ME) foi amplamente mencionada.

Como membro da CIHDOTT, eu realizo a abordagem familiar, muitas vezes, quando o diagnóstico é de morte encefálica, se a família já estiver bem orientada quanto ao protocolo, facilita todo o processo. (E7)

Quando se pensa em morte encefálica, quando se pensa em abrir protocolo, precisa comunicar a família, explicar o que é o protocolo, como ele vai ser feito, o que é a morte encefálica. Então a CIHDOTT trabalha isso de uma maneira melhor. Quando o protocolo é fechado, nem sempre a família está pronta, mas, quando participa de tudo, é fácil para a gente abordar; agora, quando a família não participa, fica um pouco mais difícil. (E5)
Durante a abordagem que realizei, pude observar a preocupação do familiar de como sua mãe ficaria e a imagem dela durante o velório. (E8)

o que eu vejo durante a abordagem é que a família tem muito medo desse paciente ficar desfigurado, ficar deformado por causa da retirada do órgão. (E9)

Muitos familiares ainda se sentem despreparados quando abordados em caso de diagnóstico de morte encefálica. A vida e a morte são dois extremos com que a enfermagem se depara todos os dias. O trabalho da enfermagem, na maioria das vezes, consiste em lutar pela manutenção da vida, mas, no caso de morte encefálica, mesmo diante da morte, os profissionais lutam pela vida, que é representada pela doação dos órgãos e tecidos ${ }^{19}$.

O conhecimento da população sobre o tema morte encefálica é limitado devido ao fato de ser pouco estudado, divulgado e discutido, o que ocasiona baixo grau de confiança relacionado a esse diagnóstico, influenciando negativamente na tomada de decisão para doação. Portanto, é de suma importância que os familiares possam acompanhar o processo de verificação de morte encefálica, não só a comunicação de conclusão do protocolo, mas todos os testes, para que seja possível constatar o óbito de seu ente. Sendo assim, é necessário que a equipe seja clara e precisa nas informações compartilhadas com essa família20,21.

A doação de órgãos e tecidos para transplante é um tema extremamente sensível e complexo pelo fato de estar diretamente relacionado aos valores morais, éticos e religiosos das pessoas. Destarte, estas se preocupam ainda com a questão do corpo e a noção de finitude. Historicamente o respeito conferido ao corpo é uma característica de nossa sociedade. O corpo representa para os familiares a memória de uma vida que deveria ser guardada, portanto não valorizar esse período significaria um desplante àquelas pessoas em seu momento de vida. Há uma real necessidade de se preocupar com o corpo como um organismo pertencente ao ser em seu conjunto de emoções e não mais como máquina, a fim de empreender uma luta contra a mecanização das ações, de forma a não somente quantificar o processo de doação e sim de qualificá-lo. Trata-se não só de um corpo onde serão retirados os órgãos para doação, mas sim, de um ser com uma historicidade, crenças e valores que teve em vida. Cabe aos profissionais agirem de forma consciente e ética, respeitando os conceitos, sentimentos e valores dos familiares ${ }^{22}$.

Os enfermeiros ressaltaram que lhes falta preparo para fazer a abordagem aos familiares do possível doador, dizem-se inseguros diante deles para a realização da entrevista, o que acaba desencadeando a perda de um potencial doador.

Eu considero que, para fazer uma abordagem hoje, eu não tenho preparo de chegar para família, porque eu acho que sucesso vem através da abordagem, e o sucesso dessa abordagem depende da segurança e do conhecimento. (E10) 
A impressão que eu tenho é que, se eu perguntar ao enfermeiro o que ele tem que falar para família, ele vai conseguir expor, mas, quando se depara com processo de abordagem, a dúvida é de como falar com a família, como chegar até essa família, como eles vão responder. Acredito que a dúvida, o medo e o receio seja esse. (E11)

A entrevista familiar se fundamenta em uma perspectiva teórico-prática e existem aspectos significativos para realização desta. Trata-se de um momento imbuído de peculiaridades e complexidades. Portanto, é um momento de extrema delicadeza, considerando que a família enfrenta impacto emocional que pode gerar resistência devido à sua perda e, muitas vezes, isso a torna incapaz de tomar as decisões. Dessa forma, cabe ao profissional a habilidade para lidar com a fragilidade da ocasião que pode ser um dos impeditivos para doação ${ }^{5}$.

Diante de tal cenário, compete aos profissionais se munirem de habilidades e conhecimentos específicos para que manejem com respeito todos os aspectos que envolvem tal processo, obtendo assim a efetivação da doação.

\section{Treinamento e capacitação}

O treinamento e a capacitação foram relatados pelos participantes do estudo como uma das dificuldades para exercer seu ofício na comissão, por não haverem obtido conhecimento prévio acerca do processo de doação e suas funções.

O que acontece é que não tive treinamento, eu tive orientações de forma muito rápida e superficial, $e$ foi uma orientação de forma verbal de como é feito quando vai a óbito. (E10)

Não houve alguma orientação ou treinamento para nos direcionar enquanto membro da CIHDOTT, não houve qualquer treinamento para que me seja orientado quanto ao meu papel, todas as minhas funções foram descobertas durante os plantões com ajuda de colegas. (E6)

Eu acho que o foco é realmente a capacitação técnicocientífica porque isso vai fazer com que a gente consiga desenvolver esse trabalho de forma mais efetiva e aí a gente consiga realmente ter um destaque dentro de Minas Gerais. (E9)

Faz quatro anos que eu estou no hospital e é recente ouvir falar de CIHDOTT dentro da instituição. Quando eu entrei no hospital, até começar a se falar em $\mathrm{ClH}$ DOTT, eu desconhecia o que é CIHDOTT, desconhecia o trabalho, então eu acho que tem muitos colegas que também não sabiam. (E10)

Eu acho que a CIHDOTT ainda precisa de uma divulgação em todas as reuniões ou panfletos explicativos para abrir a cabeça não só dos profissionais, mas geral, para conhecer realmente o processo de doação. (E4)

Estudos evidenciam déficit no conhecimento dos profissionais acerca do processo de doação e transplantes, acrescido da falta de informação sobre a existência e funcionamento das CIHDOTTs. Há real necessidade de se desenvolverem estudos que ofereçam informações esclarecedoras e baseadas em evidências sobre o funcionamento das CIHDOTTs ${ }^{3,10,18}$. Cabe destacar a existência de fragilidades no ensino de graduação em enfermagem sobre a temática ${ }^{22}$. Nesse sentido, é importante que o enfermeiro opere nesse processo, atualizando os conhecimentos, especializando-se, a fim de aprimorar o desenvolvimento de suas atividades. Além disso, cabe à coordenação da CIHDOTT das instituições disponibilizar e incentivar a capacitação desses profissionais ${ }^{23}$.

O estudo realizado nas UTIs de Toscana incluídas no Sistema Nacional de Transplantes (SNT) do Ministério da Saúde (MS) na Itália evidenciou a importância do treinamento para os profissionais atuantes com transplantes. O treinamento foi destacado como fator primordial para prevenção da recusa familiar ${ }^{24}$. Destarte, ressalta-se a importância de aquisição de conhecimentos relacionados ao transplante e doação de órgãos durante a formação, para que os profissionais adquiram destreza e conhecimento para sua atuação no campo prático ${ }^{25,26}$.

Os depoimentos dos profissionais destacam a falta de preparo e de conhecimento prévio quando inseridos na CIHDOTT, o interesse dos mesmos pelo conhecimento, mas também apontam falhas na coordenação, que não oferece educação permanente relacionada ao processo de doação na instituição. Nesse processo, a literatura aponta como fundamental a educação permanente em serviço aos profissionais atuantes nos serviços de transplantes de modo a aprimorar o trabalho desenvolvido.

\section{CONCLUSÃo}

A partir da compreensão das vivências de enfermeiros inseridos em uma CIHDOTT, foi possível verificar que a figura desse profissional é primordial para o sucesso do programa de transplantes nas instituições. Entretanto há de se considerar desafios a serem superados no decorrer de sua prática, como falta de treinamento prévio e de valorização do trabalho desenvolvido na comissão, desconhecimento dos profissionais acerca das atividades realizadas pela CIHDOTT e a sensibilização das famílias.

Destaca-se ser imprescindível o desenvolvimento de campanhas que visem à divulgação do processo de doação, bem como a realização de pesquisas sobre a temática e de educação permanente em serviço para o aprimoramento das atividades desenvolvidas pela comissão.

Como limitação deste estudo, ressalta-se que nele se procedeu à compreensão da vivência dos enfermeiros de apenas uma CIHDOTT. Destaca-se a necessidade de realização de novos estudos abordando o papel da equipe de enfermagem e da equipe multiprofissional que compõem as comissões.

\section{REFERÊNCIAS}

1. Brandalise M, Pagnuussat N. Panorama sobre os transplantes de órgãos no Brasil e fatores associados à baixa adesão à prática. Jornal Brasileiro de Transplantes. 2015; 8(2):50-5.

2. Associação Brasileira de Transplante de Órgãos (ABTO) [site da internet]. Dados numéricos da doação de órgãos e transplantes realizados por estado e instituição. [citado em 01 out 2017]. 
Disponível em: http://www.abto.org.br/abtov03/default.aspx. 3. Cappelaro J, Silveira RS, Lunardi VL, Corrêa LVO, Sanchez ML, Saioron I. Comissão Intra-Hospitalar de Doação de Órgãos e Tecidos para Transplantes: questões éticas. Revi. RENE. 2014; 15(6):949-56.

4. Freire ILS, Vasconcelos LDAQ, Torres GV, Araújo EC, Costa IKF, Melo GSM. Estrutura, processo e resultado da doação de órgãos e tecidos para transplante. Rev. bras. enferm. (online). 2015; 68(5): 555-63.

5. Garcia CD, Peireira JD, Garcia VD. Doação e transplante de órgãos e tecidos. São Paulo: Editora Segmento Fama; 2015.

6. Ministério da Saúde (Br). Portaria n. 2.600 GM, de 21 de outubro de 2009. Aprova regulamento técnico do Sistema Nacional de Transplantes. Brasil, 2009.

7. Conselho Federal de Enfermagem (Br). Portaria n. 292, de 07 de junho de 2004. Normatiza a atuação do Enfermeiro na Captação e Transplante de Órgãos e Tecidos. Brasília (DF): Conselho Federal de Enfermagem; 2004.

8. Negreiros FDS, Marinho AMCP, Garcia JHP, Morais APP, Aguiar MIF, Carvalho SL. Captação do fígado do doador para o transplante: Uma proposta de protocolo para o enfermeiro. Esc. Anna Nery Rev. Enferm. 2016; 20(1): 38-47.

9. Arcanjo RA, Oliveira LC, Silva DD. Reflexões sobre a comissão intra-hospitalar de doação de órgãos e tecidos para transplantes. Rev Bioét. 2013; 21(1): 119-25.

10. Vieira MS, Nogueira LT. O processo de trabalho no contexto da doação de órgãos e tecidos. Rev. enferm. UERJ. 2015; 23(6): 825-31. 11. Bardin, L. Análise de conteúdo. São Paulo: Edições 70; 2011. 12. Ministério da Saúde (Br). Resolução n. 466, de 12 de dezembro de 2012. Aprova as diretrizes e normas regulamentadoras de pesquisas envolvendo seres humanos. Conselho Nacional de Saúde; 2012.

13. Costa IF, Netto JJM, Brito MCC, Goyanna NF, Santos TC, Santos SSS. Fragilidades na atenção ao potencial doador de órgãos: percepção de enfermeiros. Revista Bioét. 2017; 25(1): 130-37. 14. Ferreira IR, Silva PLN, Aguiar Filho W, Gonçalves PF, Souto SGT, Oliveira VV. Doação e transplante de órgãos na concepção bioética: uma revisão integrativa. Revista da Universidade Vale do Rio Verde. 2015; 13(1): 190-203.

15. Paterson J; Zderad L. Humanistic nursing (Meta-theoretical
Essays on Practice). New York: National League for Nursing; 1988. 16. Silva RM, Santos KB, Silva GA, Reis VN, Andrade MA. Humanização da assistência em transplante de medula óssea: a percepção da equipe de enfermagem. Rev enferm REUOL. 2015; 9(6): 8261-9.

17. Lage CEB, Alves MS. (DES) Valorização da enfermagem: implicações no cotidiano do enfermeiro. Enferm foco. 2016; 7(3/4):12-6.

18. Puscel VAA, Costa D, Reis PP, Oliveira LB, Carbogim FC. O enfermeiro no mercado de trabalho: inserção, competências e habilidades. Rev. bras. enferm. (online). 2017; 70(6): 1220-6. 19. Nogueira MA, Leite CRA, Reis Filho EV, Medeiros LM. Vivência das comissões intra-hospitalares de doação de órgãos/ tecidos para transplante. Revista Científica de Enfermagem. 2015; 5(14): 5-11.

20. Costa CR, Costa LP, Aguiar N. A enfermagem e o paciente em morte encefálica na UTI. Revista Bioét. 2016; 24(2): 368-73.

21. Fonseca PIMN, Tavares CMM, Silva TN, Paiva LM, Augusto VO. Entrevista familiar para doação de órgãos: conhecimentos necessários segundo coordenadores em transplante. Online braz. j. nurs. (Online). 2016; 8(1): 3979-90.

22. Lima, Roberta, Borsatto AZ, Vaz DC, Pires ACF, Cypriano VP, Ferreira MA. A morte e o processo de morrer: ainda é preciso conversar sobre isso. REME rev. min. enferm. 2017; 36(1): 27-33. 23. Mendes KDS, Roza BA, Barbosa SFF, Schirmer J, Galvão CM . Transplante de órgãos e tecidos: responsabilidades do enfermeiro. Texto \& contexto enferm. (Online). 2013; 21(4): 945-53.

24. Piemonte G, Migliaccio ML, Bambi F, Bombardi M, Antônio LD, Guazzini A, Pasquale CD, Buoninsegni LT, Guetti C, Bonizzoli M, Bagatti L, Lopane P, Nativi A, Rasero L, Peris A. Factors influencing consent to organ donation after brain death certification: a survey of 29 Intensive Care Units. Minerva anestesiologia. 2018; 84(9): 1044-52.

25. Freire ILS, Gomes ATL, Silva MF, Dantas BAS, Vasconcelos QLDAQ, Torres GV. Aceitação e conhecimento de docentes de enfermagem sobre a doação de órgãos e tecidos. Rev. enferm. UERJ. 2016; 24(1): 155-61.

26. Lemos CLS. Educação permanente em saúde no Brasil: educação ou gerenciamento permanente? Ciênc. saúde coletiva (Online). 2016; 24(3): 913-22. 